\title{
Development and Design of a Machine Using Standard Aluminium Profiles
}

\author{
Muamer Špago, Adis J. Muminović, Nedim Pervan, Mirsad Trobradović, \\ Vahidin Hadžiabdić, Muamer Delić \\ University of Sarajevo, Faculty of Mechanical Engineering, Vilsonovo šetalište 9, \\ Sarajevo, Bosnia and Herzegovina
}

\begin{abstract}
The goal of this research is development, design and manufacturing of $\mathrm{CNC}$ milling machine prototype using standard aluminium profiles. Machine is a three axis's machine and it is developed primarily for education in the field of wood machining. It can be used also for machining of light metal parts. Main initial goal of the machine development was the low cost for its manufacturing. To achieve this goal, rapid prototyping technology was used to manufacture most of the machine parts. In addition, a lot of standard parts are used. The detail methodology for machine development, design and manufacturing are shown in this paper. Design process includes development of CAD models, calculation of all necessary critical parts, selections of materials and development of machine subassemblies and assemblies.
\end{abstract}

Keywords - machine, CNC, milling, design.

\section{Introduction}

From the beginning of the industrial revolution, a lot of different manufacturing technologies are used for manufacturing of different types of products.

DOI: 10.18421/TEM111-07

https://doi.org/10.18421/TEM111-07

Corresponding author: Vahidin Hadžiabdić, University of Sarajevo, Faculty of Mechanical Engineering, Vilsonovo šetalište No.9, Sarajevo,

Bosnia and Herzegovina.

Email: hadziabdic@mef.unsa.ba

Received: 14 October 2021.

Revised: 14 December 2021.

Accepted: 20 December 2021.

Published: 28 February 2022.

(c))BY-NC-ND (C) 2022 Muamer Špago et al; published by UIKTEN. This work is licensed under the Creative Commons Attribution-NonCommercial-NoDerivs 4.0 License.

The article is published with Open Access at www.temjournal.com
These manufacturing methods evolve through time to fulfil more and more complex demands on product development and manufacturing.

Manufacturing, from its beginning, is heavily dependent on different types of machining processes.

Machining is most used and most important manufacturing technology because of its core properties which can be used to manufacture high quality products. Especially in the field of high dimensional accuracy of a product (high dimensional and shape tolerance demands can be fulfilled). At the beginning, machining is improved through optimization of its manufacturing parameters and by introducing new and better materials for tools. Later, with the development of computers machining it is additionally improved by introducing computer numerical control (CNC). CNC machining brings additional positive properties to this manufacturing methods, such as increased efficiency, more precise manufacturing with less errors, etc. [1]

$\mathrm{CNC}$ (Computer Numerical Control) machines are controlled by computer, which represents high accuracy control, especially in combination with stepper electric motors, ball screws and high accuracy linear motion machine elements.

There is a lot of papers discussing different problems and improvements of $\mathrm{CNC}$ machines and CNC machining as a manufacturing method [2], [3], [4], [5]. Methodology for development, design and manufacturing of $\mathrm{CNC}$ milling machine prototype using standard aluminium profiles is presented in the following chapters of this paper. The same methodology is used for other product development by the same authors [6].

Machine is three axis's machine and it is developed primarily for education in the field of wood machining [7], [8]. It can be used also for machining of light metal parts. The main initial goal of machine development was low cost for its manufacturing [9]. To achieve this goal, low-cost rapid prototyping technology was used to manufacture most of the machine parts. In addition, a lot of standard parts are used. Design process includes development of CAD models [10], calculation of all necessary critical parts, selections of materials and development of machine subassemblies and assemblies. 


\section{Design Methodology Process}

\subsection{Basic Function of a Machine}

Basic function of a machine is represented as "CNC milling machine". Basic function represents dependencies of inputs and outputs of a machine (Figure 1.). Initial part and G-code are inputs of basic function and the final product is output of basic function. In the next step it is necessary to divide basic function "CNC milling machine" to its partial functions.



Figure 1. Diagram of machine basic function

\subsection{Partial Functions of a Machine}

Every basic function has several partial functions (Figure 2.). All partial functions which are essential part of one basic function needs to be executed before basic function can be executed. Partial functions are executed by machine subsystems or individual parts. All partial functions must deliver one machine function.

Partial functions can be additionally divided into elementary functions which execute more simple tasks. As early mentioned, inputs in basic function are initial part and G-code. G-code can be written by hand or generated by some of CAM (Computer Aided Manufacturing) software.

After that, first partial function can be initiated. It is a partial function for mounting of initial part inside the working space of a machine.

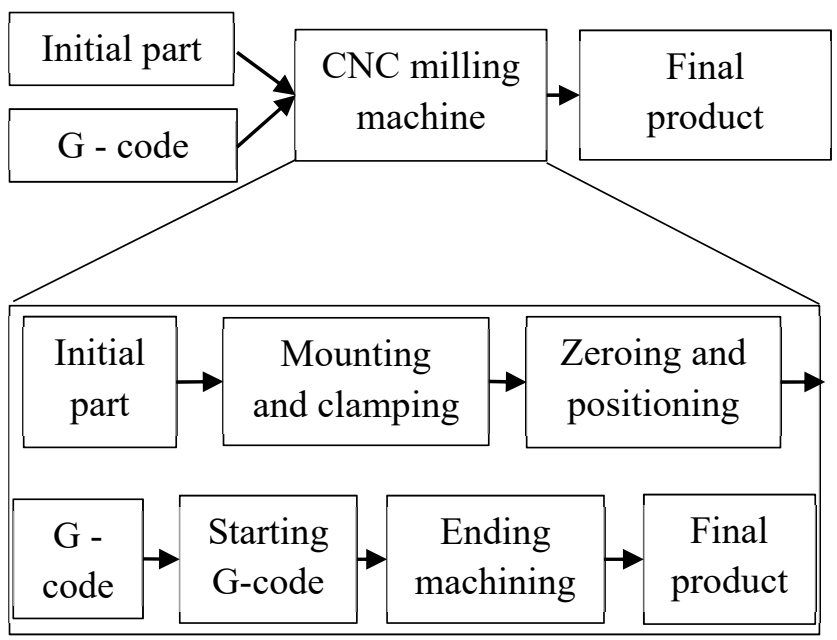

Figure 2. Diagram of machine partial functions
There are more ways to mount initial parts, it can be done using clamps, vacuum, etc. The second partial function is correction of tool length and zeroing of a machine. Different tools have different lengths and different diameters that need to be corrected during every tool change. The next partial function is used to start machining by uploading and starting G-code. After machining is done, the final product can be disassembled from the machine.

\subsection{Morphology Matrix}

Morphology matrices are used to show more different individual components which can be used to execute all partial functions (Figure 3.).

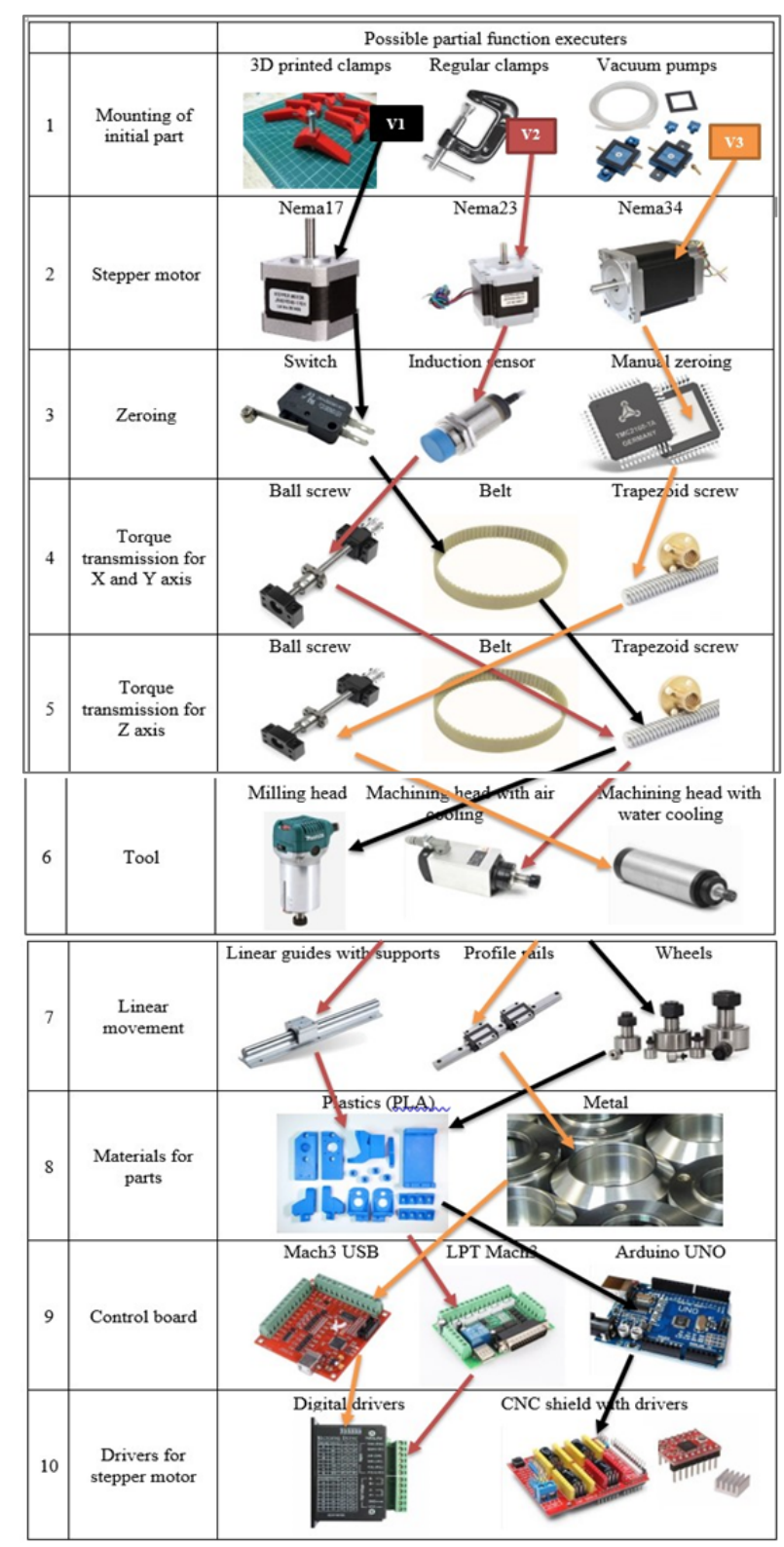

Figure 3. Morphology matrix 


\section{Concept Designs}

Figures 4., 5. and 6. show three different concept designs of a machine developed using combination of executors from morphology matrix.

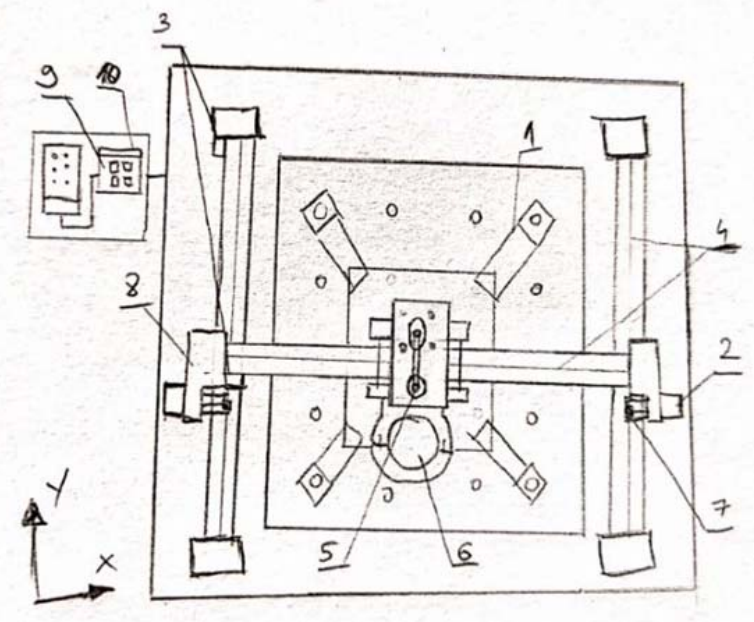

Figure 4. Concept design 1

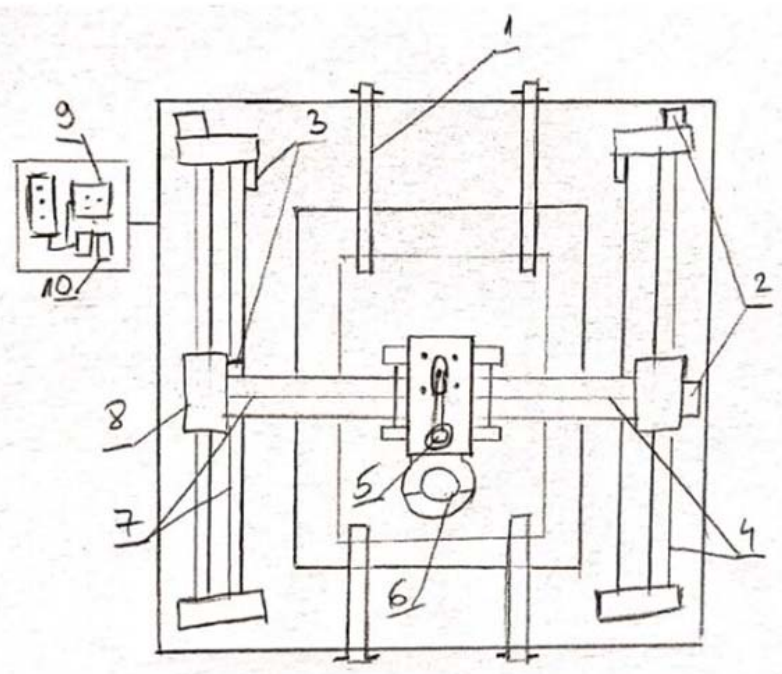

Figure 5. Concept design 2

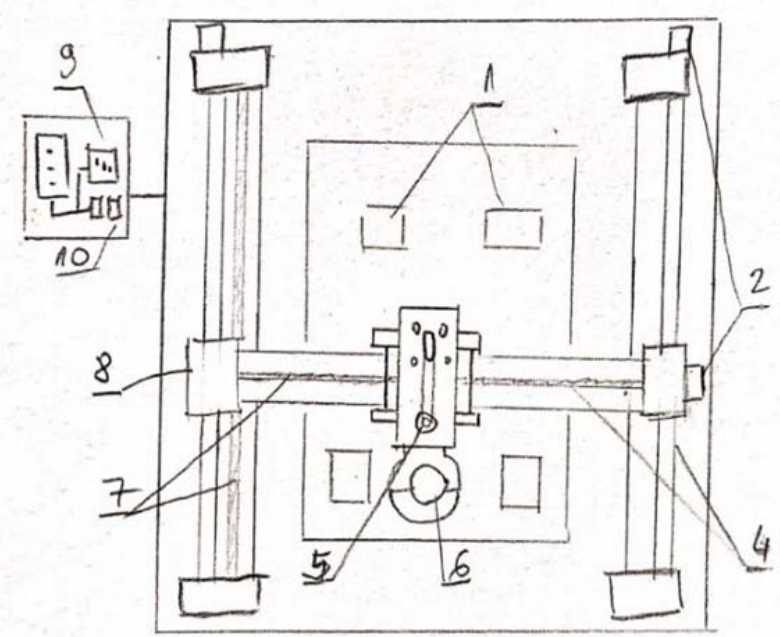

\subsection{Choosing Optimal Concept Design}

Optimal design is chosen by grading developed concept designs using technical and economic grades (Table 1.).

Table 1. Choosing optimal concept design (grades)

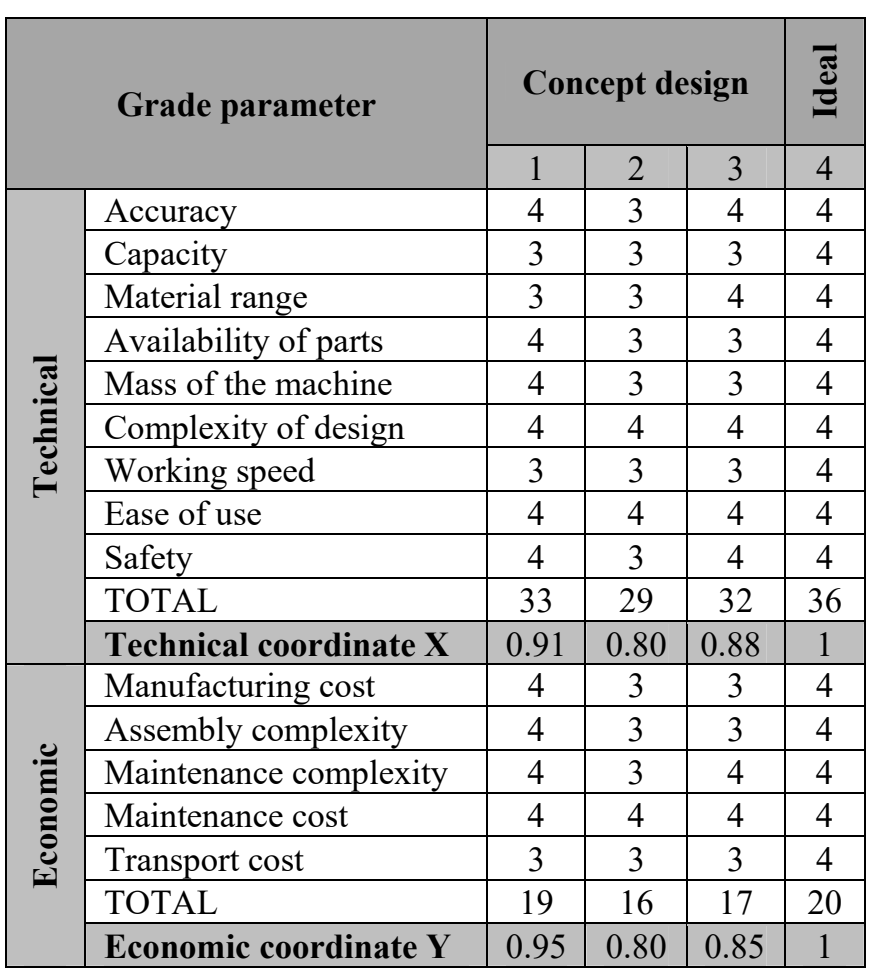

Grade from 1 to 4 is given to all parameters. Best concept design is concept design number 1 from Figure 4. It has best grades both in technical and economic coordinate (Figure 7.).

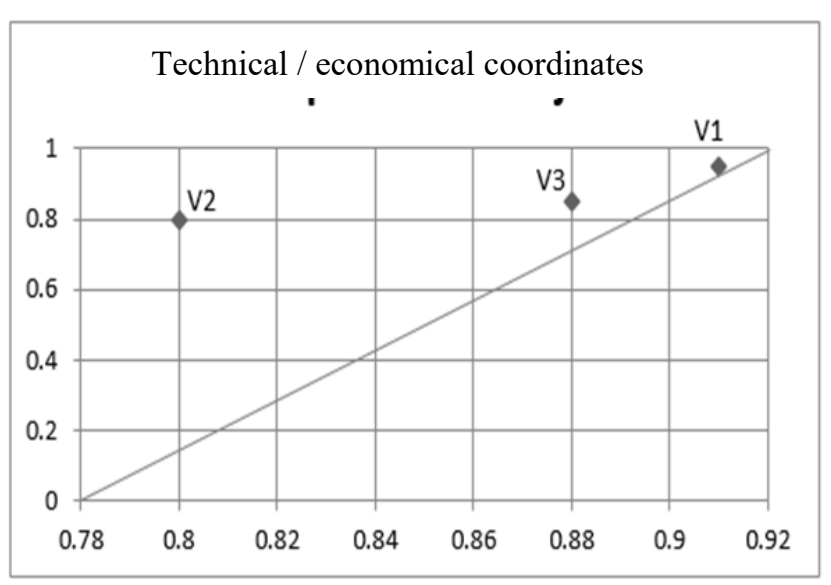

Figure 7. Choosing optimal concept design

\section{Dimensioning and Design}

CNC milling machine has four subassemblies which are explained in detail in the following subchapters of the paper.

Figure 6. Concept design 3 


\subsection{Machine Chassis}

Subassembly "Chassis" is designed and manufactured using standard metal profiles (EN10305-5). The chassis have four vertical profiles which are connected with several horizontal profiles. All profiles are connected using welding.

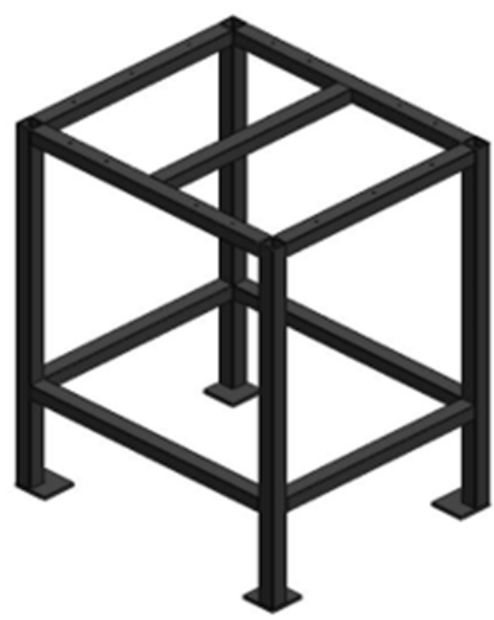

Figure 8. Machine chassis

At the top of the chassis, a wood plate is connected using standard screws (EN ISO 7049 - M5 x 50) and washers (EN ISO $7091-6$ ).

\subsection{X axis Subassembly}

This subassembly has one stepper electric motor (Nema17) with belt pulley (GT2 - 16T) which is connected to belt and wheels. The wheels are moving on the $\mathrm{V}$ groove on aluminium profiles. The belt is stationary element in this design configuration (Figure 9.). Linear movement in the direction of $x$ axis is achieved in this way. Stepper electric motor is placed from the outside of two support plates and aluminium profile is placed between these two plates.

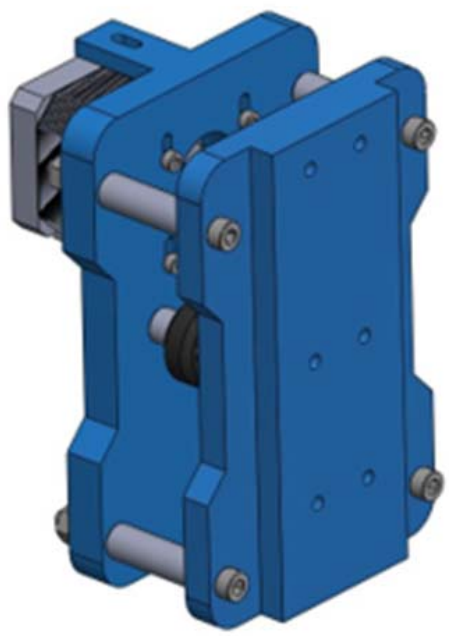

Figure 9. X axis subassembly
Support plates are connected together using screws (EN ISO 4762 - M5 x 60) and corresponding nut. Distance between these plates is defined using distance elements which are placed on the screws. Plates and distance elements are manufactured using additive manufacturing. Holes for screws for stepper electric motor connection to the left support plate are designed as long holes with the goal to enable movement of stepper motor up and down. This movement is needed because it is necessary to tighten the belt properly. At the front of the right support plate there are holes for connection of this subassembly to the aluminium profile.

\subsection{Y axis Subassembly}

For $\mathrm{Y}$ axis movement two stepper electric motors are used (Nema17). Torque transmission from stepper motor to belt is done using pulley (GT2). The belt is stationary and it is placed along the whole length of the aluminium profile (Figure 10.).



Figure 10. Y axis subassembly

Using this design, the space on the machine chassis plate is used in the best possible way. Bigger parts can be machined. Aluminium profiles are connected to the chassis plate using four supports which are manufactured using additive manufacturing and which are connected to the chassis plate using wood screws. The connection of the profiles and its supports are done using the so-called T nut. This type of connection is good because it does not demand any type of drilling of additive manufactured supports. Both stepper electric motors have its own supports, one on the left and one on the right side. These supports are also manufactured using additive manufacturing. Inside these supports there are wheels which are used to move the whole $\mathrm{Y}$ axis subassembly along aluminium profiles. All wheels are supported using standard metal ball bearings with a goal to reduce the friction. There are two wheels, one from above and one from below aluminium profile. 


\subsection{Z axis Subassembly}

For $\mathrm{Z}$ axis movement, stepper electric motor is used (Nema17), same as for $\mathrm{X}$ and $\mathrm{Y}$ axis. This time the torque is transmitted to trapezoidal screw using micro belt and two pulleys (Figure 11.).

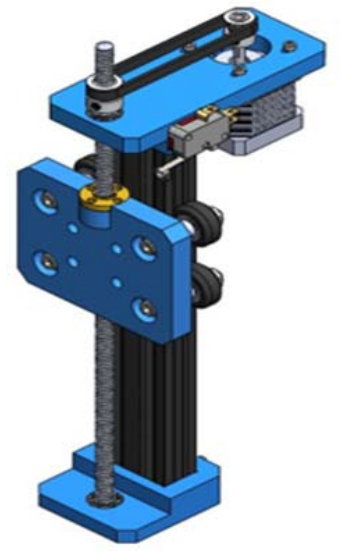

Figure 11. Z axis subassembly

Trapezoidal screw has brass nut which is connected to the support plate with a hole on it for tool holder connection. The nut and trapezoidal screw have a function to transform rotation movement of the stepper electric motor to translation movement of the support plate and tool.

\subsection{Tool Holder Subassembly}

Tool holder subassembly has front and back supports connected using screws (EN ISO $4762-$ M5 x 20). The whole subassembly is connected to $Z$ axis subassembly again using screws (EN ISO 4762 - M5 x 25) (Figure 12.).

The tool holder can be designed in different ways, this type is chosen because it is simple and practical. It must have good stiffness for more precise tool holding. In addition, tool holder must enable tool movement up and down along the $\mathrm{Z}$ axis.

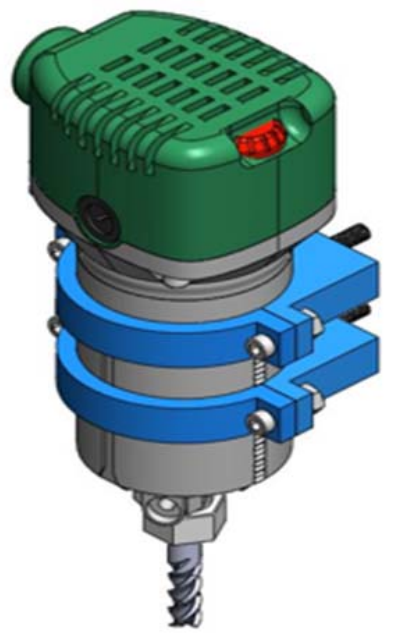

Figure 12. Tool holder subassembly

\subsection{Control unit Subassembly}

Control unit subassembly is a place where all electric components will be placed. It is necessary to design a housing for power supply, stepper electric motors, control board and buttons for starting and ending the machining process.

For machine control, Arduino Uno board and CNC shield are used. This is the most used electronics by most of the manufacturers and hobby machine developers. G-code is generated using regular computers, transferred to the Arduino using USB or card memory. CNC shield regulates all machine processes (Figure 13.).



Figure 13. Control unit subassembly

\section{Design Calculations}

\subsection{Selection of Tool Electric Motor}

To select power electric motor for milling, it is necessary to calculate power which is needed for wood milling. This power is depended on several factors like the depth and width of the milling, speed movement of the tool and type of material which needs to be machined. The power of the electric motor needed for milling can be calculated using the power which needs to be used for milling divided by electric motor efficiency [11]:

$$
P_{M}=\frac{P_{C}}{\eta}=166,67[W]
$$

Where:

$P_{M}$ - power of electric motor,

$P_{C}$ - power needed for milling,

$\eta$ - electric motor efficiency (usually it is from $80 \%$ to $90 \%$ ).

Power for milling can be calculated using the following equation:

$$
P_{C}=\frac{a_{p} \times a_{e} \times v_{f} \times k_{c}}{60 \times 10^{6}}=150[W]
$$


Where:

$$
\begin{aligned}
a_{p}=1 \mathrm{~mm} & - \text { milling depth, } \\
a_{e}=6 \mathrm{~mm} & - \text { milling width, } \\
v_{f}=6000 \mathrm{~mm} / \mathrm{min} & - \text { tool speed movement } \\
k_{c}=250 \mathrm{~kg} / \mathrm{mm}^{2} & - \text { milling pressure on tool } \\
& \text { for wood milling. }
\end{aligned}
$$

From equation 1, it can be seen that minimal power for wood milling is $166,67 \mathrm{~W}$. If any of the above-mentioned parameters are changed, the power of the electric motor must be changed accordantly. Except power, it is necessary to calculate the electric motor speed. Recommended milling speed is usually around 2000 up to 15000 RPM. Makita RT0700C electric motor is chosen with the power of $710 \mathrm{~W}$ and speed in range from 10000 up to 30000 RPM.

\subsection{Selection of Stepper Electric Motors for $X, Y$ and $\mathrm{Z}$ axis}

As previously mentioned, for machine axis movement, the stepper electric motors are used. They are good for this type of application because it is possible to control their rotation movement very precisely. To select this type of electric motor moment of inertia, torque and RPM needs to be calculated. Stepper motors are usually selected using $\mathrm{kgcm}$ units instead of Nm units, and because of that, the following calculation is adopted to $\mathrm{kg}$ and $\mathrm{cm}$ units.

In the case where the power is transmitted using belt and pulley, the moment of inertia can be calculated using the following equation [12]:

$$
\begin{gathered}
\mathrm{J}_{\text {tootal }}=\mathrm{J}_{\text {motor }}+\left(\left(\mathrm{J}_{\text {pulley }}+\mathrm{J}_{W}\right) / i^{2}\right) \\
\quad=2,856 \cdot 10^{-5} \mathrm{~kg} \mathrm{~m} \mathrm{~s}{ }^{2}
\end{gathered}
$$

Where $\mathrm{J}_{\text {motor }}, \mathrm{J}_{\text {pulley }}, \mathrm{J}_{W}$ and $i$ are selected and calculated according to [10].

Needed torques for starting and running can be calculated according to the following equations:

$$
\begin{gathered}
T_{\text {acc }} \approx \mathrm{J}_{\text {tootal }} \times(\Delta \text { speed } \div \Delta \text { time }) \times 0.1 \\
\approx 6,857 \cdot 10^{-3} \mathrm{~kg} \mathrm{~m} \\
T_{\text {run }}=\left(M_{\text {tootal }} \times r\right) / i \\
=4,181 \mathrm{kgcm} \\
M_{\text {tootal }}=M_{\text {ext }}+M_{\text {friction }}+M_{\text {gravity }}+M_{C} \\
=6,433 \mathrm{~kg}
\end{gathered}
$$
[10].

where all parameters are selected according to

The speed of stepper electric motor can be calculated according to the following equation [12]:

$$
R P M=\frac{a}{360} \cdot f_{Z} \cdot 60=2400 \mathrm{RPM}
$$

Where:

$$
\begin{aligned}
a=360^{\circ} / \mathrm{N}=1,8^{\circ} & - \text { rotation per step, } \\
N=200 \mathrm{step} / \mathrm{rev} & - \text { resolution of stepper } \\
& \text { motor, } \\
f_{z}=8000 \mathrm{~Hz} & - \text { frequency of impulse } \\
& \text { signals of stepper electric } \\
& \text { motor. }
\end{aligned}
$$

Needed torque of the stepper electric motor is:

$$
T_{\text {motor }}=T_{\text {acc }}+T_{\text {run }}=4,867 \mathrm{kgcm}
$$

This value of torque is the minimal value which the stepper motor needs to have. For $\mathrm{Y}$ axis two electric motors are used, and because of that the stepper motor NEMA 17 with torque value of $4,3 \mathrm{~kg}$ $\mathrm{cm}$ can be selected.

Same calculation can be done for $\mathrm{X}$ and $\mathrm{Z}$ axis. Loads for $\mathrm{X}$ axis are the same as for $\mathrm{Y}$ axis but in this case only one motor is used. Because of that, the stepper motor NEMA 23 with torque value of 11,90 $\mathrm{kg} \mathrm{cm}$ is selected. The same stepper motor is selected for $\mathrm{Z}$ axis because the forces for wood drilling are much lower in comparison to the forces of milling. In addition, all design elements on $\mathrm{Z}$ axis have much lower mass in comparison to the $\mathrm{X}$ axis.

\section{Manufacturing and Testing}

Manufacturing of machine parts is carried out using rapid prototyping technologies (additive manufacturing) using Ultimaker 3 machine. The first step in the manufacturing process is to create STL file from developed 3D CAD model. In the next step it is necessary to import STL file to software Ultimaker CURA where the G-code for manufacturing needs to be generated. Before generation of the G-code, it is necessary to select manufacturing parameters, select orientation of the part inside the machine and select material which will be used for part manufacturing. All parts are manufactured using PLA (Polylactic acid) material. One of the milling machine parts manufactured inside Ultimaker 3 is shown in Figure 14.

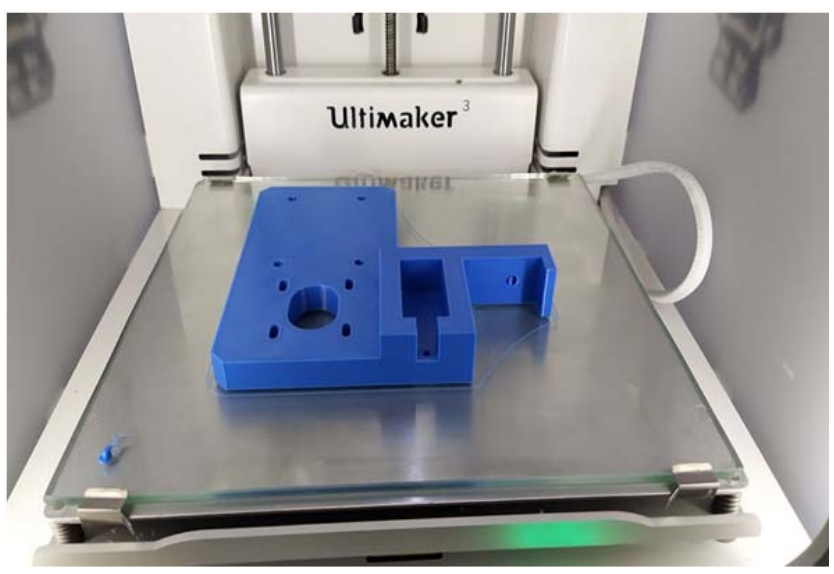

Figure 14. One part of the milling machine manufactured using Ultimaker 3 




Figure 15. Machine stand

For the machine stand (Figure 15), steel profiles $70 \times 50 \mathrm{~cm}$ are used. These profiles are connected using welding. The stand has adjustable legs for levering process.

The basic parts of design for axis subassemblies are three aluminium profiles $45 \times 45 \mathrm{~mm}$ with a length of $550 \mathrm{~mm}$ ( $\mathrm{X}$ and $\mathrm{Y}$ axis) and $300 \mathrm{~mm}$ length ( $\mathrm{Z}$ axis) (Figure 16.). Aluminium profiles are supported by two supports on each side and they are connected to these supports using $\mathrm{T}$ screws and nut. Height of profiles for $\mathrm{Y}$ axis is $80 \mathrm{~mm}$ which is enough for proper machine functions. Same design solution is used for $\mathrm{X}$ axis profiles support. In this case supports are designed to support aluminium profiles and to hold stepper motors.

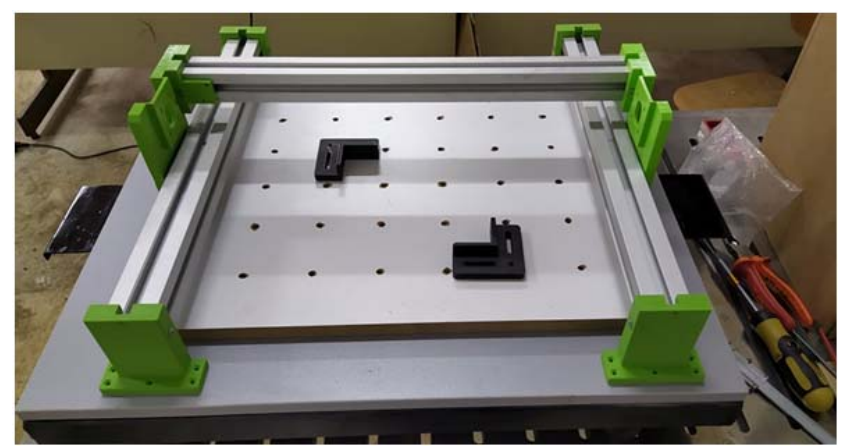

Figure 16. $X$ and $Y$ axis subassemblies

$\mathrm{Z}$ axis subassembly has one vertically oriented aluminium profile which is connected to $\mathrm{X}$ axis using two supports (Figure 17.). The tool is connected to the rest of subassembly using two connectors. Inside diameter of these connectors is the same as outside diameter of the tool. Connectors are mounted using DIN 912 screws (M6x25).

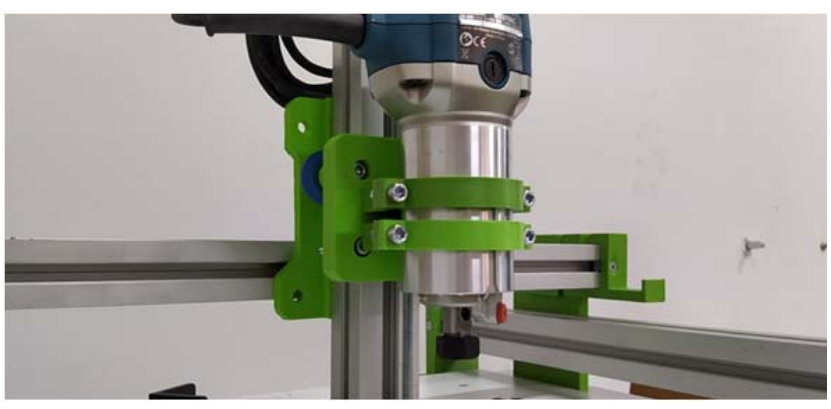

Figure 17. Z axis subassembly

For machine control, the GRBL software is used. This software is uploaded to the Arduino board which controls the stepper motors. The GRBL software translates the G-code to stepper motor movements.

The designed, developed and manufactured milling machine is shown in Figure 18.

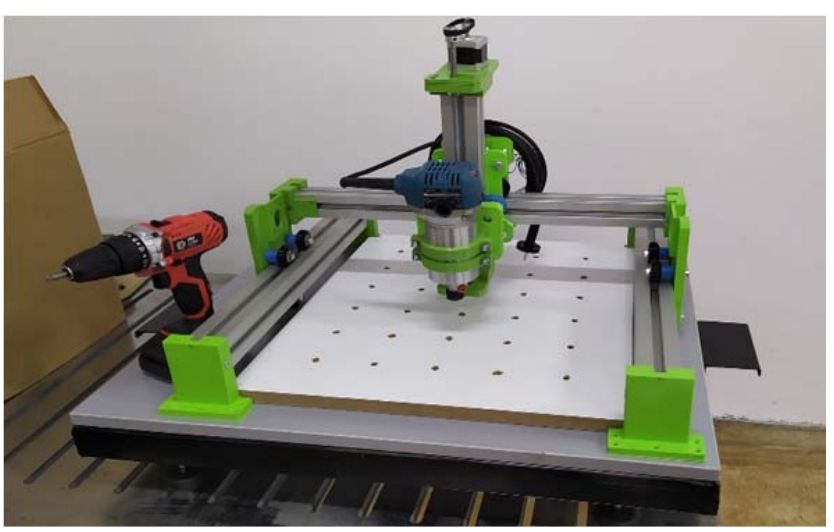

Figure 18. Manufactured milling machine

\section{Conclusion}

In this paper, development, design and manufacturing of milling machine prototype, using standard aluminium profiles, is shown and described in detail. The whole methodology for new product development and design is shown, from initial concept design, through the development of CAD models up to manufacturing of real fully functional prototype.

The goal of the research was to develop and manufacture real fully functional prototype of milling machine which can be used for wood machining for hobby users and for teaching purposes for people and students who have a goal to enter the world of numerical computer control machining.

The methodology for new product design and development presented in this paper can be used for design, development and manufacturing of any new product. Rapid prototyping technology enables easy manufacturing of complex parts and assemblies. This can be used for fast manufacturing of real fully functional products, especially products which will be used in educational purposes. 


\section{References}

[1]. Kopač, J., \& Bahor, M. (1999). Interaction of the technological history of a workpiece material and the machining parameters on the desired quality of the surface roughness of a product. Journal of Materials Processing Technology, 92, 381-387. https://doi.org/10.1016/S0924-0136(99)00239-3

[2]. Zhang, Z., Cheng, Q., Qi, B., \& Tao, Z. (2021). A general approach for the machining quality evaluation of S-shaped specimen based on POS-SQP algorithm and Monte Carlo method. Journal of Manufacturing Systems, 60, 553-568. https://doi.org/10.1016/j.jmsy.2021.07.020

[3]. Salem, A., Hegab, H., \& Kishawy, H. A. (2021). An integrated approach for sustainable machining processes: Assessment, performance analysis, and optimization. Sustainable Production and Consumption, 25, 450-470. https://doi.org/10.1016/j.spc.2020.11.021

[4]. Zhengyang, X. U., \& Yudi, W. A. N. G. (2021). Electrochemical machining of complex components of aero-engines: Developments, trends, and technological advances. Chinese Journal of Aeronautics, 34(2), 28-53. https://doi.org/10.1016/j.cja.2019.09.016

[5]. Singh, G., Aggarwal, V., \& Singh, S. (2021). Experimental investigations into machining performance of Hastelloy C-276 in different cooling environments. Materials and Manufacturing Processes, 36(15), 1789-1799. https://doi.org/10.1080/10426914.2021.1945099
[6]. Smajic, J., Muminovic, A. J., Saric, I., \& Muminovic, A. (2021, June). Development and Design of a Machine for Hybrid Manufacturing. In International Conference "New Technologies, Development and Applications” (pp. 121-134). Springer, Cham. https://doi.org/10.1007/978-3-030-75275-0 15.

[7]. Tseng, A. A., Kolluri, S. P., \& Radhakrishnan, P. (1989). A CNC machining system for education. Journal of Manufacturing Systems, 8(3), 207-214.

https://doi.org/10.1016/0278-6125(89)90042-3

[8]. Valvo, E. L., Licari, R., \& Adornetto, A. (2012). CNC milling machine simulation in engineering education. Int J Online Biomed Eng, 8(2), 33-8. https://doi.org/10.3991/ijoe.v8i2.2047

[9]. Song, X., Pan, Y., \& Chen, Y. (2015). Development of a low-cost parallel kinematic machine for multidirectional additive manufacturing. Journal of Manufacturing Science and Engineering, 137(2). https://doi.org/10.1115/1.4028897

[10]. Saric, I., Muminovic, A., Delic, M., \& Muminovic, A. J. (2020). Development of integrated intelligent CAD system for calculation, designing and development of bridge crane. Journal of Applied Science and Engineering, 23(2), 349-355. https://doi.org/10.6180/jase.202006 23(2).0018

[11]. Sremić, D. (2017). CNC glodalica za izradu tiskanih pločica (Doctoral dissertation, University of Zagreb. Faculty of Mechanical Engineering and Naval Architecture).

[12]. Automation Direct.(2021). SureStep Stepping Systems User Manual, Seventh Edition, Revision C. Retrieved from: https://cdn.automationdirect.com/static/manuals/surest epmanual/surestepmanual.pdf [accessed: 10 September 2021]. 